\title{
Developing a Graphical Route Information Panel (GRIP) for use on the UK motorway network. The first steps $s$.
}

\author{
Shalloe, S.C. Sharples, G. Burnett, D. Crundall, Meekums, D. Morris
}

This paper appeared in Transportation Research Part F 27 (2014) 133-149 and all copyright remains with the journal

\begin{abstract}
This paper describes the initial stages of research to develop design guidelines and draft designs for Graphical Route Information Panels to be used on the UK motorway network to display traffic congestion information. The studies utilised a funnelling approach to initially capture the broad design principles involving all stakeholders and then narrow down the design options using a range of validation and evaluation activities to achieve the desired design guidelines. Guidance for graphical road based display design is presented along with a methodological approach for the implementation of new designs.
\end{abstract}

\section{Introduction}

Advances in technology have increased the range of display options available on electronic message signs commonly used on road networks to display information to drivers. In the UK, variable message signs (VMS) have traditionally provided traffic information by means of text based messages. The development of sign technology has enabled the display of pictograms and multi-coloured graphical representations. Driver compliance with route recommendations through existing systems such as text based VMS are limited in the amount of information they can provide and often do not produce the desired level of diversions. However compliance generally increases with the level of information given (Schönfeld, Reischl, \& Tsavachidis, 2000).

In 2009, the UK Highways Agency commissioned a program of research and development into using Graphical Route Information Panels (GRIPs) to display traffic congestion information. This paper describes the initial stages of a project to develop design guidelines and draft designs for GRIPs to be used on the UK motorway network to display traffic congestion information. This involved a literature review to identify any design guidelines for GRIPs followed by workshops to develop design guidelines, produce draft design ideas and identify and prioritise research questions and project constraints. A series of scenario based research studies followed to evaluate the draft designs. Subsequent eye tracking studies were reported in Crundall, Crundall, Burnett, Shalloe, and Sharples (2011). The aim of the work was to develop understanding of the impact of the increased information and new form of representation on driver attitude and predicted behaviour. The contributions of this paper are an insight into design requirements for graphical representations of traffic congestion information and demonstration of a user- 
centred funnelling approach to incorporate a range of stakeholder views, beliefs and evaluations in the formative design of novel information displays.

\subsection{Background literature}

A GRIP, unlike a traditional electronic variable message sign, allows any type of text or graphical representation, or a combination of both, to be displayed. Consequently, symbols, traffic signs and route maps can be displayed (Lai, 2012). Published research specifically related to the design and evaluation of GRIPs for use on the UK network is limited. GRIPs are a relatively new innovation in driver information provision, especially within Europe. The application and operation of graphical traffic information exists in other countries but, in particular the research from Japan or China, may not translate well to Europe due to local differences including legislative frameworks for new types of traffic signs and the cultural and educational backgrounds of drivers who may better comprehend complex graphical signs (Schönfeld et al., 2000). Evaluation studies of GRIPs in terms of their effects on traffic flow (Gan, 2010) and route choice (Dicke-Ogenia, Coffeng, \& Brookhuis, 2008; Gan \& Chen, 2013) have shown the effectiveness of GRIPs but the designs used may not be appropriate for use on the UK network due to differences in signage legislation, language and panel design. The panels in the UK on which the designs created by this work would be displayed used two-colour limited LED arrays (192_ 128 resolution).

Relevant literature sources to inform GRIPs design includes good principles of display design, research into graphical representations of roadways and electronic representations of maps. A GRIP can be considered primarily as an information source but it can also serve as a warning sign if additional text or pictograms are displayed to advise of hazards and as a navigational map as it may display a representation of the road network ahead. Therefore general principles of display design for warnings or information signs will also apply. Wickens, Lee, Liu, and Gordon Becker (2004) set out general display design principles that are relevant in informing the design of GRIPs including perceptual principles, keeping consistency with users' mental models of the system being displayed, avoiding designs which would be too distracting to drivers and including those which help support drivers memory of traffic information using strategies such as repetition of information and consistent coding of information across signs.

GRIPs offer increased potential to display colour is useful as "for identification tasks colour was found to be superior to all forms of coding except alphanumeric codes" (Hughes \& Creed, 1994, p. 1871). Monmonier (1996) discuss that for pictorial symbols red is often used as a warning and for environmental hazards the sequence red-yellow-green is often employed. Colour can also facilitate faster visual searching (Raskin, 2000) although imperfect colour vision can produce misleading perceptual effects (Monmonier, 1996) and care is needed that the use of colour is not confusing or distracting Southworth and Southworth (1982).

One opportunity that GRIPs offer is the display of a map-type representation of forthcoming road patterns. This has the potential to support driver decision making and route choice, 
especially when traffic congestion or road closure occurs. Depiction of the roadway has been addressed by Agrawala and Stolte (2000) who identified four design goals of readability, clarity, completeness and convenience necessary for the production of successful computer generated route maps. They argue that demonstrating the curvature, the path and the length of the route is unnecessary as people will 'distort' these things when making a route map, and then maintain these distortions in their own mental model of the route. They conclude that handdrawn maps are a good example of route maps which are clear and concise and accommodate the necessary design goals. These tend to focus on start and end points and highlight points of reorientation clearly; they distort the route in such a way that only salient features are shown and use variable scaling in order to show those features clearly (however, if one road is longer than another, this should be shown). Line size can be used to represent magnitude, for example thick lines can suggest different road classifications (Monmonier, 1996). However the extent to which this guidance could be translation to a resolution- limited large screen on-road display needed to be established. Issues of map orientation, north or heading up, were investigated by Mashimo, Daimon, and Kawashima (1993). They found that even when a person has a good knowledge of a route, the characteristics of spatial orientation still influenced the outcome, and this has important implications for the design of road signs and GRIPs. Research into in-car navigation devices has produced human factors guidelines for the design of these devices map orientation state that displays should be able to be changed based on whether the driver is using the device for planning or for route guidance (Campbell, Carney, \& Kantowitz, 1998). As GRIPs are static displays outside the vehicle, the transferability of research from handheld or incar maps is not clear, highlighting the need for specific research which is described in Crundall et al. (2011). Although the primary aim of a GRIP is not as a navigational aid, any map based representation will contain navigation information. Additional detail may negatively impact route recall for drivers unfamiliar with the area but for drivers with prior knowledge of the route, relevant additional detail e.g. landmarks, can help with the recall of route information (Sanchez \& Branaghan, 2009). Some studies have specifically considered the use of electronic signs to display graphical representations of traffic conditions. In the UK, Richards, McDonald, Fisher, and Brackstone (2004) recommended that GRIPs should use a heading-up orientation and colour coding alone should not be used to discriminate between items displayed e.g. use size and colour to distinguish between congestion levels. However no precise or agreed overall design guidelines were reported. Their reported findings into driver comprehension of GRIPs and possible distraction effects were limited however they found that headingup orientation was confusing to some drivers; a majority of drivers believed the colour green on some signs highlighted the quickest route rather than indicating levels of traffic congestion and that where journey times were displayed on road segments on a GRIP, there was disagreement about which portion of the road the journey time referred to.

Gan, Sun, Chen, and Yuan (2006) provide outline guidance in relation to the design of GRIPS including generic statements such as the layout should be concise, easy to understand, be credible and comply with ergonomic principles. In addition they recommend that map 
distortions which distort the sense of driver's distance should be avoided; the displayed network should take into account the origin-destination characteristics of the sign location and should cover as wide a region as possible. Items such as symbols, text style and roads should have a consistent design across signs. Other research has found that the level of detail that participants required indicated a discrepancy between desirable user requirements and what was technically possible due to limitations of clarity and legibility (Brave \& de Baar, 2009). Other studies such as those by Aitken, Conway, and Walton (2012) have reported on the outcomes from their work including cognitive studies to produce prototype designs for the US but do not detail how the prototype design decisions were formulated. Regarding specific design guidelines, research by Schönfeld et al. (2000) in Bavaria suggested that drivers generally used destination names for their orientation rather than geographical terms such as North or West. In the UK, both forward destination names and directional indicators are used. They also found that displaying both directions of traffic in only some parts of the network was ambiguous and let to misinterpretation and recommended that parts of the network not being monitored by the driver should not be shown. They also found that drivers thought that time details displayed referred to travel time rather than delay time although Alkim, van der Mede, Janssen, and Control (2000) argued that travel times should not be displayed as they cluttered the sign. The issue of consistency needs careful consideration here, as travel time is increasingly used on the UK road network and so user expectations are likely to have adjusted. Whilst the use of red and green was widely understood to indicate levels of traffic congestion (Schönfeld et al., 2000, Ullman, Chrysler, Dudek, Trout, \& Ullman, 2008; Aitken et al., 2012), the use of yellow was not (Schönfeld et al., 2000). This presents a conflict in terms of display conspicuity, where yellow on a black background can offer on the highest contrast representations. Other recommendations included that signs should be displayed heading up (Alkim et al., 2000; Schönfeld et al., 2000), should be schematic (Schönfeld et al., 2000) with relative proportions of the network displayed as accurately as possible (Alkim et al., 2000) and minor roads should be indicated by thinner lines (Alkim et al., 2000). Alkim et al. (2000) recommended A 'you are here' arrow should be included. Road number and direction should be displayed independently (Alkim et al., 2000) and road names should be placed on the roadway (Ullman et al., 2008). Empirical work recorded that displaying three traffic queues on a GRIP produced the longest decision distances for drivers after reading the sign (Alkim et al., 2000) although they were less likely to slow down when approaching a GRIP compared to a text based VMS (Alkim et al., 2000). Only two colours should be used on the sign, red to depict congestion and black to indicate free flowing traffic (Schönfeld et al., 2000). There should be heading on signs e.g. TRAFFIC INFO (Schönfeld et al., 2000) and a sign advising drivers of new information signs ahead should be installed to alert drivers of their use (Schönfeld et al., 2000). There is some evidence regarding the extent to which drivers trust or rely on GRIPs in decision making. Studies into the effects of GRIPs on driver behaviours showed approximately $40 \%$ of drivers said they selected their route based on the information displayed on the GRIP, with this rising to $50 \%$ for some people on particular routes (Brave \& de Baar, 2009; Dicke-Ogenia et al., 2008; Gan et al., 2006) with good map readers using the information for route choice decisions more than poor 
map readers (Alkim et al., 2000). Drivers quickly learned what the information on a GRIP meant and as familiarity increased, expressed preference for them against a text based variable message sign (Alkim et al., 2000) Brave and de Baar (2009) although those aged under 25 or over 70 needed increased exposure to the signs to fully understand them (Brave \& de Baar 2009). There was no potential safety risk identified in simulator studies (Schönfeld et al., 2000) (van der Mede, Coffeng, Martens, Janssen, \& Alkim, 1999) and overall GRIPs did not appear to result in higher loading on drivers than text based VMS and were interpreted reasonably well (Ullman et al., 2008).

This paper describes a series of structured activities that were conducted to inform design of Graphical Route Information Panels for use on the UK road network. The study is the first systematic testing of different design elements and layout principles that has been conducted in the UK. The work presented here contributes new knowledge of driver requirements for the depiction of traffic congestion information to support driver decision making using two colour limited LED array panels.

\section{Methodology}

A mixed methods approach was adopted to capture input from a variety of stakeholders. The range of methods ensured the participatory development of prototype designs for representation of traffic congestion and road network layouts and provided data to evaluate these designs. Table 1 lists the methods and the order in which they were carried out. The studies utilised a funnelling approach to initially capture the broad design principles involving all stakeholders and then narrow down the design options using a range of validation and evaluation activities to achieve the desired design guidelines. Three initial focus groups were held to investigate potential designs of GRIPs with a range of stakeholders and to provide indepth subjective data about existing designs from other countries (along with one draft UK design). These data, along with recommendations from the literature review, were used to produce the first draft GRIP designs. These were refined and evaluated in subsequent scenario studies. Ethical approval for the study was obtained from the Ethics Committee of the Faculty of Engineering, University of Nottingham. The motorway network around Birmingham, a major UK city, was chosen for the development of the GRIPs design. 2.1. Academic expert focus group

The first focus group was held at the University of Nottingham with six experts from the fields of human factors; psychology; geospatial and computer science. Participant baseline knowledge of the Birmingham motorway network was assessed and then participants completed a number of tasks: drawing a simple diagram for a driver to use to navigate; designing a suitable graphical display to indicated traffic congestion status to drivers; the rating of each design followed by group discussion to evaluate each design, provide draft guidelines for designs and identify further research needs.

\subsubsection{Results from academic expert focus group}


Of the six draft designs produced, four were based on a map representation of the motorway network, one was based on road layouts which did not represent a map and another was purely text based. None of the designs included place names. Of the four map based designs, one depicted the network as a squared off figure of eight, two used only straight lines and two used curved or wavy lines to depict the motorways. Two used single lines and two used double lines to depict motorways and road name labels were generally placed alongside the road lines. Subsequent group discussions were based around a number of topics and a summary of these along with along with a summary of the conclusions are shown in Table 2.

\subsection{Driver and industry expert focus groups}

Two further workshops with drivers and one with transportation, industry and signage experts were held at the University of Nottingham. For the driver workshop, 17 participants were recruited in response to adverts placed at the University, nine female and eight male with a mean age of 40 years ( $s d=12.4)$. Participants had held a full UK driving licence on average for 17.1 years $(s d=9.1)$; drove on average 8375 miles per annum and half drove on UK motorways at least 1-2 days each week. Only two had either never or rarely driven in the Birmingham area. Each workshop took $1.5 \mathrm{~h}$ and participants were paid an inconvenience allowance for taking part. The final workshop was arranged with 11 industry experts taking part. The average age of these participants was 40 years $(s d=12.4)$ and there were seven male and two female participants. Participants had held a full UK driving license on average for 23 years $(s d=12.7)$. Five participants drove on UK motorways 1- 2 days a week and four participants drove on motorways in the Birmingham area 1-2 days a week. All had driven in that area at some time.

\subsubsection{Activity 1}

The first activity involved participants studying a map of the Birmingham motorway network. They were asked to imagine they had a job interview in a suburb of Birmingham. Participants were first asked to state which motorways they felt they needed to know traffic information about, including the direction of the motorway and junction numbers. Secondly they were asked to indicate which of the following types of information they would like to obtain from a road sign: length (in miles) of traffic queues; expected delay time (minutes); current travel time (minutes); reasons for any delays; location by junction numbers of any traffic queues. They were also asked to state whether there was any other information they felt should be shown.

\subsubsection{Results}

There was variety in the motorways about which participants wanted information. The majority wanted information about the most direct routes however almost half wanted information about all possible routes. The results for the type of information drivers would like to see on a sign advising of traffic conditions are shown in Table 3. The most requested type of information was location of any delay followed by delay time (in minutes). Just over half the participants wanted to know the travel time and length (in miles) of any traffic queues.

\subsubsection{Activity 2}


Participants sketched a simple diagram for drivers, showing the motorway network around Birmingham and mark on any information they felt drivers would need.

\subsubsection{Results.}

Fifteen out of 26 participants drew a representation using only straight lines. Of the other 11 , six used smooth curves and five used 'wiggly' lines (more representative of roads drawn on a map). Two participants drew their map 'heading up' whereas all others used a 'north up' orientation. This was expected as the participants were not given details of a specific journey drivers would be taking. All but one participant placed road name labels next to the road represented and 11 put the word "Birmingham" in the centre of the map; eight included some other place names, shown in different colours to the road names and two included some landmarks.

\subsubsection{Activity 3}

Participants were divided into small groups and were presented with instructions to produce a draft GRIP to be displayed to drivers approaching the Birmingham motorway network. Each group was later asked to explain the rationale behind their design.

\subsubsection{Results}

Eight of the nine groups produced a design showing a map based schematisation of the motorway network. One produced a text based design. Five designs showed only half of the motorway network i.e. did not include the roads they did not intend to drive on to reach their destination. All eight map based designs used straight lines. Seven designs had a location ('you are here') arrow and seven out of the eight showing a road network were designed 'heading up'. All map based designs showed road numbers alongside the roadway, with only one group naming 'Birmingham' on the sign and one showing destination names. One group noted the two major landmarks on the signs and another noted motorway service stations. Six groups either changed the colour of the roadway to red to indicate the location of congestion or placed red blocks next to the roadway. One group used orange blocks next to the roadway and another used red chevrons to indicate slow traffic leading up to the congestion site. One drew a hazard warning sign at the site of the congestion and another placed a pictogram at the centre of the sign to indicate the reason for the delay. One group included travel time information to the congestion site and also on alternative routes and another group included delay time information.

\subsubsection{Activity 4}

Participants were shown a series of images of existing and draft GRIP designs and were asked their opinions on each. These were chosen to provide a range of design ideas and examples to help participants understand and assess different options.

\subsubsection{Results}


The images used and a selection of participant comments are shown in Table 4. Overall sign 1 received the most favourable comments about the road network representation, with sign 5 receiving the second most number of favourable comments. The manner in which the problem area was highlighted in sign 5 was noted as being good by the majority of participants. The labelling of road numbers in sign 3 and place names in sign 5 were also well regarded. The design of the location ('you are here') arrow was liked in sign 5 . Signs 4 and 1 received negative comments in relation to the amount of information displayed and the use of colour in sign 5 was most disliked.

\subsubsection{Activity 5}

This involved a group discussion and voting on a number of topics relating to the GRIP designs. Key findings from the group discussions were that a 'you are here' arrow should be included with no representation of route already driven showing. Blocks of red and yellow should indicate congestion severity with the background roadway colour being unchanged where there was free-flowing traffic. Participants were more interested in time delay than distance indicators and all wanted clear, uncluttered signs, easy to read at speed. Relevant motorway junction numbers should be displayed and trunk roads only on view if they were to be used as an alternative route. Participants wanted road numbers displayed and most expressed a preference for a heading-up orientation as with current UK road signs. Straight lines were preferred to depict the roadway with rough approximations of road length. Multiple queues could be displayed if they were relevant to drivers and colour coded for simplicity. Participants felt that only congestion on driver's side of carriageway should be indicated on GRIPs unless otherwise essential and the majority wanted to see both road and place names on the GRIP. Some requested that travel times for alternative routes should be indicated.

\subsection{Production of draft designs}

The findings from the literature reviews and focus groups were used to develop a number of draft GRIPs designs. Five basic roadway layout designs were chosen representing the Birmingham motorway network. The design elements of four of the designs were:

- Design Aa: All paths (roads) straight, nodes symmetrical around X/Y axis,

- Design B: All paths (roads) straight, nodes and paths around junctions positioned accurately,

- Design C: Paths (roads) represent gross curves of roadway, nodes and paths around junctions positioned accurately,

- Design D: Paths (roads) represent more detailed curves, nodes and paths around junctions positioned accurately.

These designs were to be presented to participants 'North up'. A further design, chosen from the focus group studies, was also selected (Design A) and this was presented 'Heading up' as this layout could not be translated into a 'North up' display. The industry expert focus group 
had identified a set of constraints and assumptions associated with future sign designs. One constraint, the technical specification of the electronic sign on which any GRIPs would be displayed, was also taken into account, specifically ensuring that the appropriate colours were used and that the images were created using the same number of pixels as LEDs are available on the current electronic signs. Current legislation regarding text displayed on road signs was also taken into account when producing the designs.

The designs are shown in Fig. 1. Each design was developed in four basic forms; as shown below, with junction indicators, with driver location indicators and with both junction and driver location indicators. An example of design $\mathrm{C}$ incorporating both driver location (arrow) and junction indicators can be seen in Fig. 2 .

Five different representations of traffic congestion were chosen to be included in the next phase of the study, based on the findings from the literature review and the focus group studies, as shown in Fig. 3. Six different representations of road closures were also chosen to be included in the next phase of the study, as shown in Fig. 4.

\subsection{Scenario studies}

Two scenario studies took place at the University of Nottingham. The first was designed to examine the attitude of users to the range of different designs, and the second examined their comprehension of sign meaning.

\subsubsection{First scenario study}

\subsubsection{Participants}

Thirty-eight participants, 21 male and 17 female, were recruited from responses to posters and emails and consisted of a mixture of staff from local businesses and organisations, University of Nottingham staff and students. All participants had held a full UK driving licence on average for 15.9 years, were aged between 21 and 65, average age 38.7 years, and had driven on a UK motorway within the last six months and drove on average 10,302 miles per year.

\subsubsection{Procedure}

The study took place in the Human Factors Simulation laboratory at the University of Nottingham. Participants were first presented the basic network designs using a PowerPoint presentation projected onto a screen and were asked to fill in their responses to a number of questions on a response sheet. The questions included ranking the designs in order of preference, ease of understanding, any comments or suggestions and deciding whether additional elements should be included in the designs. Their favourite network design was then displayed with junction indicators and participants were again asked about their preference for the design with or without this element. Depending on their response, their preferred design was then presented with a driver location indicator (with or without the junction indicators) and again their preference was noted. Following this, their preferred design, with or without 
the additional indicators was presented with all of the congestion representations followed by all of the closure representations and each time the participant's responses were collected. Participants were then presented with the M6 designs and asked questions about their preferences, ease of understanding and any other comments they had about the designs. Each participant was paid an inconvenience allowance for taking part in the study. 2.4.1.3. Results

\subsection{Network design preference.}

Participants were asked in Question 1, "Please rank the designs in order of preference, with 1 being the one you think best represents the motorway network and 5 being the one you think least well represents the motorway network". This wording was chosen to elicit responses specifically about the representation of the actual road layout rather than other design elements such as lettering or colour. A Friedman test was applied to the data and there was a significant overall effect of design ( $\mathrm{Xr} 2=16.61, \mathrm{n}=38$, df $=4, \mathrm{p}<0.05)$. Design $\mathrm{C}$ was ranked highest in terms of preference, followed by $B, D$ and Aa. Design A was the least preferred design.

A series of Wilcoxon tests were applied to identify which of the designs were statistically equivalent in terms of ranked preference and the following were found to be equivalent (i.e. not significantly different to each other at $p<0.05$ ): $A$ and $A a, A$ and $D, A a$ and $D, B$ and $C, B$ and $D$. These homogenous subsets are illustrated by the hoops in Fig. 5 . There were significant differences at $p<0.05$ between $A$ and $B\left(W(38)=184.50, Z=\_2.734, p<0.05\right), A$ and $C(W(38)$ $\left.=182.00, Z=\_2.760, p<0.05\right), A a$ and $B\left(W(38)=166.50, Z=\_3.131, p<0.05\right), A a$ and $C(W(38)$ $\left.=173.50, Z=\_2.90, p<0.05\right)$ and $C$ and $D\left(W(38)=111.00, Z=\_4.219, p<0.05\right)$.

\subsection{Comments about basic designs}

Participant comments about the basic designs were analysed using theme based content analysis (Neale \& Nichols, 2001). The main themes for basic designs identified were: (a) how much the images represented either maps or the actual road, (b) simplicity versus the need for a certain level of detail and (c) orientation of images.

Five participants stated they preferred designs $C$ and $D$ because they were map-like and therefore familiar, making them easier to interpret quickly. The fact that these maps were representative of the actual terrain was also cited by three people, easily translating to their personal 'mental map'.

Design A received mixed reviews. It was not widely favoured, as it was not considered to be truly representative of the terrain. However, several people $(n=6)$ did like the fact that the straight lines made it very simple to look at, and also that it helped in understanding driver location relative to the network. Comments were also made that it should be correctly orientated (i.e. heading-up), as if it was incorrectly orientated according to direction of travel this would make it confusing. 
In terms of simplicity, there was a mix of attitudes. Three people felt that they would prefer simplification of the image by the use of straighter lines, as this is easier to interpret when travelling at speed. There were also comments that $C$ and $D$ were 'too detailed or complex', and this simplification was what seemed to be popular about Design A. However, others remarked that they were unused to such straight lines, with one person saying that $A$ was 'over-

simplified'. Ultimately the theme emerging was that some detail was helpful, but that too much would be difficult to take in when moving at speed. The two most popular designs, C and B, seemed to be a compromise between not enough detail and too much detail. Two participants remarked that the labels were not clearly mapped onto the routes presented. 2.4.1.3.3. Network design ease of understanding. Participants were also asked, "Please rank the designs in order of how easy you think they are to understand when you are driving past them, with 1 being the easiest to understand and 5 the most difficult." A Friedman test was applied to the data and there was a significant effect of design ( $X r 2=15.579, n=38, d f=4, p<0.05)$. Design $B$ was ranked as the easiest to understand, followed by $C, A a$, then $D$.

Design A was ranked as the most difficult to understand. A series of Wilcoxon tests were applied to identify homogenous subsets in terms of ranked preference and the following were found to be equivalent (i.e. not significantly different to each other at $p<0.05$ ): $A$ and $A a, A$ and D, Aa and D, B and C. These are illustrated by the hoops in Fig. 6, which illustrates the average rankings of ease of understanding of the network designs.

There were significant differences at $p<0.05$ between: $A$ and $B(W(38)=176.50, Z=\ldots 2.8 .9, p<$ $0.05), A$ and $C\left(W(38)=205.00, Z=\_2.426, p<0.05\right), A a$ and $B\left(W(38)=181.00, Z=\_2.901, p<\right.$ 0.05), Aa and C $\left(W(38)=227.50, Z=\_2.105, p<0.05\right), B$ and $D\left(W(38)=174.00, Z=\_2.904, p<\right.$ $0.05), C$ and $D\left(W(38)=129.50, Z=\_3.918, p<0.05\right)$.

\subsection{Additional design features}

Participants were asked whether they preferred the designs to have junction indicators and/or driver location arrows. The majority of participants $(n=30)$ preferred designs to include junction indicators and a driver location indicator $(n=35)$.

\subsection{Traffic congestion designs}

Participants were asked "Thinking about how traffic congestion could be displayed on the sign, please rank the different designs in order of how well you think the design indicates that there is traffic congestion ahead". The results from the rankings of the congestion designs are shown in Fig. 7.

A Friedman test was carried out and there was a significant effect of design $(\mathrm{Xr} 2=116.989, \mathrm{n}=$ $38, d f=4, p<0.05)$. Congestion design 4 was ranked as the best representation of traffic congestion, followed by designs 5, 2 and 1. Design 3 was ranked as the worst representation of traffic congestion. A series of Wilcoxon tests were applied to identify homogenous groups and the following were found to be equivalent (i.e. not significantly different to each other at $p<$ 
$0.05): 1$ and 3, 4 and 5. There were significant differences at $p<0.05$ between 1 and $2(W(38)=$ $\left.56.00, Z=\_4.786, p<0.05\right), 1$ and $4\left(W(38)=0.00, Z=\_5.451, p<0.05\right), 1$ and $5(W(38)=0.00$, $\left.Z=\_5.532, p<0.05\right), 2$ and $3\left(W(38)=130.00, Z=\_3.590, p<0.05\right), 2$ and $4(W(38)=0.00, Z=$ _5.504, $p<0.05), 2$ and $5\left(W(38)=9.00, Z=\_5.360, p<0.05\right), 3$ and $4\left(W(38)=5.00, Z=\_5.476\right.$, $\mathrm{p}<0.05), 3$ and $5\left(\mathrm{~W}(38)=11.50, \mathrm{Z}=\_5.271, \mathrm{p}<0.05\right)$.

The main themes which emerged from the theme based content analysis on traffic congestion were: (a) the use of colour and (b) the thickness of lines used. Around half the participants specifically commented that it was a good idea to use the colour red to identify something relevant occurring on the road, as the eye is immediately drawn to it. It was interpreted as an indicator of a problem (one person felt that it might suggest an accident). However, three people queried whether red may prove to be a problem for drivers who were colour-blind. Designs 1 and 2 were not well received, as the location of the congestion indicator was perceived to be alongside the road and not actually on it, with one person saying that they thought the line might represent a 'fragment of road'.

Design 3 was generally considered to be confusing, with almost a third of people remarking that the congestion indicator was unclear as it was the same colour as the route representation (i.e. yellow) and that it appeared to be on just one side of the carriageway. One person felt that designs 2 and 3 'suggested only northbound congestion'.

It was felt that design 4, with the thicker red line indicating congestion, stood out more clearly than in design 5. However, a couple of participants commented that they were not sure whether the thickness of the line meant something else, such as a possible road closure.

\subsection{Road closure designs}

Participants were asked "Thinking about how road closures could be displayed on the sign, please rank the different designs in order of how well you think the design indicates that there is a road closed ahead". A Friedman test was applied and there was a significant effect of design ( $\mathrm{Xr} 2=87.925, \mathrm{n}=38, \mathrm{df}=5, \mathrm{p}<0.05)$. Closure design 7 was ranked the best representation of a road closure, followed by numbers $11,9,10$ then 6.

Design 8 was ranked the worst representation of a road closure. A series of Wilcoxon tests were applied to identify homogenous subsets and the following were found to be equivalent (i.e. not significantly different to each other at $p<0.05): 6$ and 10, 7 and 9, 7 and 11, 9 and 11 . These are illustrated by the hoops in Fig. 8 which illustrates the average rankings of the closure designs. There were significant differences at $\mathrm{p}<0.05$ between 6 and $7(\mathrm{~W}(38)=17.5, \mathrm{Z}=$ _5.170, $\mathrm{p}<$ $0.05), 6$ and $8\left(W(38)=169.00, Z=\_3.00, p<0.05\right), 6$ and $9\left(W(38)=87.00, Z=\_4.148, p<\right.$ $0.05), 6$ and $11\left(\mathrm{~W}(38)=112.50, Z=\_3.766, p<0.05\right), 7$ and $8\left(W(38)=13.00, Z=\_5.225, p<\right.$ $0.05), 7$ and $10\left(W(38)=83.00, Z=\_4.196, p<0.05\right), 8$ and $9\left(W(38)=3.50, Z=\_5.425, p<\right.$ $0.05), 8$ and $10\left(W(38)=168.00, Z=\_2.987, p<0.05\right), 8$ and $11\left(W(38)=44.00, Z=\_4.035, p<\right.$ $0.05), 9$ and $10\left(W(38)=96.50, Z=\_4.035, p<0.05\right), 10$ and $11\left(W(38)=38.50, Z=\_4.894, p<\right.$ $0.05)$. 


\subsection{Comments about road closures}

The main themes emerging in this section were: (a) the use of the colour red; (b) use of a 'gap' to represent closure and (c) the 'cross' and 'bar' symbols. In the case of road closures, again it was generally considered to be a good idea to use the colour red to represent this, with 11 participants commenting that red made it clearer and quicker to comprehend. As before, however, several people $(n=3)$ pointed out that this may be an issue for those drivers who suffer from colour-blindness.

One person thought that it was potentially confusing to use red to represent both congestion and closure. Six participants remarked that they liked the 'gap' being used to represent road closure, but one or two people felt that the road being 'rubbed out' was not easy to interpret and that it may possibly have other meanings. Two favourable comments were made about the use of the 'cross' indicator. It was felt that the cross was good in that it was a distinct symbol from that used for traffic congestion, and also that it could be used either without the addition

of the colour red or with a gap, but that it would still be clear on its own. Two of the participants were confused by designs 8 and 9, which used a 'dash' or 'bar' alone to represent closure, as they were unsure whether the symbol might mean a bridge or junction.

2.4.1.4. Discussion. Basic network designs $B$ and $C$ were ranked as the favourite designs, with design $D$ being ranked equally to notionally second place design $B$. Designs $C$ and $D$ used nonstraight lines (with varying degrees of deviation from a straight line, based on topographic information) to depict the road network whereas design B used straight lines. Both designs had the nodes and paths around the motorway junctions displayed accurately. All of these designs were presented in a north-up orientation to participants but the issue of whether designs should be presented north or heading-up was not investigated in this study (see stage four of this report for comparison of orientation options). Designs B and C were ranked as equally easy to understand. In addition, the majority of participants preferred the network designs to include junction indicators and a driver location indicator (arrow).

The joint favourite congestion designs were those that used a red line on the carriageway to depict congestion, with the red marking either being the same width or wider than the carriageway. Around half of the participants specifically commented that they felt it was a good idea to use a red colour to identify that something relevant was being displayed on the road. There were three road closure designs which received statistically equivalent rankings in terms of preference; the design displaying a red cross, the design with a red bar and gap in the roadway and the design with just a red bar across the roadway.

Again participants generally felt that the colour red should be used to depict a road closure. There were mixed responses to use of a gap to depict road closure with some participants believing it meant either that the road itself was incomplete or that there was a problem with 
the sign or that it could mean a bridge or junction. Overall the designs which emerged as the strongest were $B$ and $C$ with participants finding them easiest to understand and although they used different roadway depictions both used nodes and paths around junctions which were positioned accurately.

\subsubsection{Second scenario study}

The aim of second section scenario study was to investigate people's comprehension of a range of GRIP designs and to investigate the potential effects of these designs on route choice behaviour. The designs chosen for this section of the scenario studies were informed by the results of the first section of the scenario studies and from consultation with the project sponsors. Designs B and C were selected along with the most popular representations of traffic congestion and road closure were selected. In addition, the most popular single colour representations of traffic congestion and road closure were chosen to be included in this stage of the project. These elements were retained in case there was a requirement to implement a grip using a single colour display.

\subsubsection{Method}

2.4.2.1.1. GRIP designs. It was decided that this study would be carried out using GRIP designs that were based on the same major city but using fictional place names and road numbers to reduce possible biases in route choice behaviour which could be caused by local knowledge of the actual road network. A copy of the network map can be seen in Fig. 9. The GRIPs were designed to be displayed heading up in two travelling conditions, one based on drivers approaching the network from the M92 westbound with their destination being Redville and the second with the driver approaching on the M36 northbound, heading to Brunton. A majority of participants preferred the network designs to include junction indicators and driver location arrows so these were included in the GRIP designs. The congestion and closure representations chosen were the two dual colour and the single colour designs which were ranked highest in the design building study. The dual colour congestion designs used were the same size and wider red line designs and the single colour congestion design was the one with the yellow line alongside the roadway. The dual colour closure designs were the red $\mathrm{X}$, red bar and the red bar with a gap in the roadway. The single colour closure design was the yellow bar with a gap in the roadway. This resulted in 28 GRIP designs being created. Examples of the designs can be seen in Fig. 10. The GRIPs were designed to be displayed heading up and then superimposed onto a photograph of a sign located at the side of a motorway as seen in Fig. 11. These images were presented to participants using a PowerPoint presentation, displayed on a computer screen. The images were adjusted to attempt to replicate the resolution of a display that would be perceived when implemented on an MS4 in a real world context. The order in which images were presented to participants was balanced in six study conditions and participants were randomly assigned to one of the study conditions. 


\subsubsection{Study procedure.}

The hour long study also took place at the University of Nottingham. Participants were paid an inconvenience allowance. Participants were first given a paper map of the network to study. They were told their first destination and asked to write down the route they would take and memorise it. Once the participants were confident they knew the route, the map was removed and they saw the first image of a GRIP, which was displayed for six seconds. Participants then wrote down their answers to the following questions: _ What you think the sign means? _ Why you think that? _ Which route would you take? _ Why did you choose that route? The researcher also noted any comments participants made about the signs they saw or about their interpretation of the signs. Participants then viewed each of the different designs using different destinations. Finally participants were asked which designs they thought were easiest to understand, to rank the traffic congestion and road closure designs in order of ease of understanding, how useful they thought the signs would be if displayed after a text based VMS and whether the signs should be displayed heading or north up.

\subsubsection{Participants. Thirty-two participants, 18 male and 14 female, were recruited from} responses to posters and emails and consisted of a mixture of staff from local businesses and organisations, University of Nottingham staff and students. All participants had held a full UK driving licence on average for 15.6 years, were aged between 21 and 65, average age 36 years, and had driven on a UK motorway within the last six months and drove on average 11,800 miles per year.

2.4.2.4. Accuracy of sign interpretation. Participants were asked what they thought each GRIP closure design meant and their responses were rated as either completely correct, shows some idea of the problem but the wrong reason given, no idea or no answer, or completely incorrect. These were coded as 2 for a completely correct response, 1 if partially correct, 0 if no response or had no idea and 1 if completely incorrect. Initial analysis using Wilcoxon tests showed no significant difference $(p<0.05)$ depending on whether the designs were presented using the M36 and M92 road network. There was also no significant effect of GRIP design on the accuracy of interpretation $(p<0.05)$.

2.4.2.4.1. Traffic congestion representation. The means of interpretation ratings for the congestion designs are shown in Table 5. When considering the individual congestion designs, a Friedman test was carried out on the ratings and a significant effect of congestion representation was found $(X 2=47.583, d f=2, d f<0.05)$. A series of Wilcoxon tests were applied to identify which of the designs were statistically different. Congestion design 4 was significantly more accurately interpreted than design $1, W(32)=0.00 \mathrm{Z}=\_4.871, \mathrm{p}<0.05$. Design 5 was significantly more accurately interpreted than design $1, W(32)=2.5, Z=\_4.821, p$ $<0.05$. There was no significant difference in the accuracy of interpretation between congestion designs 4 and 5. 2.4.2.4.2. Qualitative analysis on traffic congestion representation. Data was 
collected on the reasons why people interpreted the designs in a particular way and theme based content analysis was carried out on this data. The most prevalent themes are detailed in Table 6.

2.4.2.4.3. Road closure representations. The means of the interpretation ratings for the road closure designs are shown in Table 7. A Friedman test was carried out on the ratings and a significant effect of closure representation was found $(X 2=12.773, d f=3, p=0.005)$. A series of Wilcoxon tests were applied to identify which of the designs were statistically different. Significant differences were found between closure designs 7 and $10(W(32)=86, Z=$ 3.185, $p$ $<0.05)$, and 9 and $10\left(W(32)=109, Z=\_2.731, p<0.05\right)$. Closure design 7 achieved greater accuracy ratings than design 10. Design 9 achieved greater accuracy ratings than design 10; design 10 achieved greater ratings than design 11 . There were no significant differences between designs 7 and 9, 7 and 11 and designs 9 and 11 i.e. in other words, closure representations 7,9 and 11 were statistically equivalent.

2.4.2.4.4. Qualitative analysis on traffic closure representation. Data was collected on the reasons why people interpreted the designs in a particular way and theme based content analysis was carried out on this data. The most prevalent themes are detailed in Table 8 below.

2.4.2.4. Discussion. There was no significant difference between the accuracy of driver responses to congestion or closure designs depicted on network design $B$ when compared to when depicted on network design $C$ indicating that the road network design did not affect how accurately participants rated the congestion or closure designs. Congestion designs 4 and 5 produced significantly more accurate responses than congestion design 1 . There were no significant differences between closure designs 7,9 and 11 and all three produced significantly more accurate responses than closure design 10, Analysis on participant stated route choice behaviour was carried out and there was no effect of network map design (i.e. M36 vs. M92) on route choice behaviour. However, participants were more likely to change their route when designs were presented on design $B$ rather than on design $C$.

2.4.2.5. Second scenario study overview. As a result of this stage of research, designs $B$ and $C$ were identified as those that were most preferred and yielded best understanding, with some indication that participants were more likely to change their route when presented with congestion or closure information on design B compared to design C. The preferred representation of road congestion was a red line, either the same width as or slightly wider than the road width, and three types of representations of road closure were also identified as most easy to comprehend. On the basis of this data, the designs which participants found easiest to understand were then identified for use in the later work stages, namely the eye tracking (Crundall et al., 2011) and driving simulator studies. 


\section{Conclusions}

The designs for GRIPs are constrained by a number of factors including the hardware configuration, legislation, location, conspicuity and operational issues along with a range of human factors including ease of understanding, speed of travel, driver motivation and familiarity. These studies have produced two potential designs for GRIPs to display traffic congestion or road closure information using signs which are only able to display either one or two colours on a black background using a limited LED array. Although some findings may be largely specific for the UK road network, some are generalizable and the methodological approach can be adopted in any country.

\subsection{Guidance for road-based graphical display design}

Some generalisable findings emerge from this work. Designs $B$ and $C$ were the most preferred and yielded the highest rate of understanding by drivers on first viewing. There was some indication that drivers were more likely to change their route when presented with congestion or closure information on design B compared to design C. Our results were not completely consistent with those of Agrawala and Stolte (2000) who found in their work using computer generated route maps that representation of curvature and length of route was unnecessary. In the GRIPs context our results suggest (consistent with Gan et al., 2006) that where the opportunity to represent a complete network is available, information about road curvature and relative distance improves comprehension and acceptance. It was also evident that there were individual differences in preferences for and comprehension of different roadway representations; it is possible that the value of the more complex representation of road curvature is associated with aesthetic preference as well as comprehension.

Our results clearly showed a preference for a 'heading up' representation, consistent with Schönfeld et al. (2000) and Alkim et al. (2000); and a further study that we conducted using eye-tracking methodologies (Crundall et al., 2011). All design stakeholders also expressed a requirement for the inclusion of a 'you are here' arrow. The best colour for representation of road closure was found to be red, either a bar or a cross (perpendicular to the roadway), with or without a gap in the roadway either side of the closure. The best representation of an area of congestion was depiction in red, either the same width or slightly wider than the roadway.

\subsection{Methodological approaches to road-based graphical display design}

Our results suggest agreement with the findings of Brave and de Baar (2009) who note that the level of detail participants required showed a discrepancy between desirable user requirements and what was technically possible in terms of complexity and legibility. This demonstrates the need to always test such displays in simulated and real-world contexts to ensure that any compromises in design that take place due to technical limitations are correctly chosen and implement. For example, it is important to consider the design trade-off between detail of representation of road layout and amount of network displayed. 
Our provisional results using driving simulation (not reported in this paper) and other studies that have examined different graphical designs (Schönfeld et al., 2000; van der Mede et al., 1999; Ullman et al., 2008) have not found a major impact of GRIPs on driver distraction. However, as technology develops, it is likely that the potential for representing more complex displays will become available. At this point it is increasingly important that simulator trials to investigate driver distraction and comprehension are conducted. Therefore we can propose the following stages when introducing new graphical display designs into road networks.

Ensure minimum requirements for compliance with legislation: This may include consideration of signage conspicuity, location and font size.

Identify the optimal level of complexity: This requires balancing technological constraints and opportunities with desire for representation of complete road networks and traffic information with implications for driver distraction and time taken for comprehension.

Test sign designs with users to consider comprehension, acceptance and predicted impact on driver behaviour: A structured approach such as the scenario approach presented in this paper offers a cost-effective and comprehensive method to obtain early results and allow funnelling of design options, whilst retaining involvement and input from multiple stakeholder groups. Results from previous studies on conventional VMS (Sharples, Shalloe, Burnett, \& Crundall, 2013) have demonstrated consistency between predicted behaviour in scenario studies and measured behaviour in simulator studies.

Assess impact of signs on driver distraction using simulators: As complexity of sign design increases it is important that individual signs and the implementation of sets of different signs are evaluated in a simulated context to ensure that there continues to be no negative impact of these signs on driver distraction.

The methodology used in the study proved successful with successive phases of the design process being evaluated by drivers. The involvement of different stakeholder groups has benefit in terms of acceptance of future sign designs and ensures that different perspectives, ranging from business to behavioural considerations, are reflected early in the design phase. It is important to consider culturally specific aspects when considering integrating new technologies into existing transport networks - much opinion and behaviour regarding road sign information is influenced by past experience, and this needs to continue to be reflected in electronic graphical displays.

\section{Acknowledgments}

The views expressed in this paper are solely those of the authors and do not necessarily represent the views of the Highways Agency or Mott MacDonald. The work presented in this paper was funded by the Project Support Framework and conducted in partnership with Mott MacDonald for the UK Highways Agency. The authors would particularly like to thank Paul Whitehead and Masud Hussain for their support in the work presented in this paper. 


\section{References}

Agrawala, M., \& Stolte, C. (2000). A design and implementation for effective computergenerated route maps. In AAAI Technical Report SS-00-04.

Aitken, R. J., Conway, A., \& Walton, M. (2012). Implementing Graphic Route Information Panels (GRIPs) in the United States. ITE Journal, 42-47.

Alkim, T. P., van der Mede, P. H. J., \& Janssen, W. H. (2000). Graphical route information on variable message signs. In Road Transport Information and Control, 2000. Tenth International Conference on (Conf. Publ. No. 472), pp. 32-36.

Brave, E., \& de Baar, A. (2009). Road users positive about graphical congestion information on bermDRIPs. Netherlands, Rijkswaterstaat - DVS Centre for Transport and Navigation, communication from Whitehead, P. Highways Agency, March 2009.

Campbell, J. L., Carney, C., \& Kantowitz, B. H. (1998). Human factors design guidelines for Advanced Traveler Information Systems (ATIS) and Commercial Vehicle Operations (CVO). US Department of Transportation, Federal Highway Administration. Report number FHWA-RD-98057. Accessed at http:// www.fhwa.dot.gov/tfhrc/safety/pubs/atis/index.html, 6 April 2009.

Crundall, D., Crundall, E., Burnett, G., Shalloe, S., \& Sharples, S. (2011). The impact of map orientation and generalisation on congestion decisions: a comparison of schematic-egocentric and topographic-allocentric maps. Ergonomics, 54(8), 700-715.

Dicke-Ogenia, M., Coffeng, G., \& Brookhuis, K. A. (2008). Improved access to cities through travel information on full color information panels. European Transport Conference, Leeuwenhorst Conference Center, The Netherlands.

Gan, H. C. (2010). Graphical route information panel for the urban freeway network in Shanghai, China. IET Intelligent Transport Systems, 4(3), 212-220. Gan, H. C., \& Chen, S. (2013). Why Do Drivers Change Routes? Impact of Graphical Route Information Panels. ITE Journal, 83(8), 38-43.

Gan, H. C., Sun, L. J., Chen, J. Y., \& Yuan, W. P. (2006). Advanced traveler information system for metropolitan expressways in Shanghai, China. In Transportation Research Record: Journal of the Transportation Research Board, No. 1944, pp. 35-40.

Hughes, P. K., \& Creed, D. J. (1994). Eye Movement Behaviour viewing colour-coded and monochrome avionic displays. Ergonomics, 37(11), 1871-1884. Lai, C.-J. (2012). Drivers' comprehension of traffic information on graphical route information panels. Accident Analysis and Prevention, 45, 565-571.

Mashimo, S., Daimon, T., \& Kawashima, H. (1993). Driver's characteristics for map information representation (North up Map/Heading up map) in Navigation Displays. In Proceedings of IEE Vehicle Navigation and Information Systems Conference, Ottawa. 
Monmonier, M. (1996). How to lie with maps. Chicago: The University of Chicago Press. Neale, H., \& Nichols, S. (2001). Theme-based content analysis: a flexible method for virtual environment evaluation. International Journal of Human Computer Studies, 55(2), 167-189.

Raskin, J. (2000). The human interface. New directions for designing interactive systems. London: Addison-Wesley. Richards, A., McDonald, M., Fisher, G., \& Brackstone, M. (2004). Investigation of driver comprehension of traffic information on graphical congestion display panels using a driving simulator. European Journal Transport and Infrastructure Research, 4, 417-435.

Sanchez, C. A., \& Branaghan, R. J. (2009). The interaction of map resolution and spatial abilities on map learning. International Journal of Human Computer Studies, 67, 475-481.

Schönfeld, G., Reischl, A., \& Tsavachidis, M. (2000). Dynamic driver information goes graphical A new quality in urban traffic information. In: Proceedings of the 7th World Congress in Intelligent Transport Systems, 2000, Turin, Italy. Brussels, ITS Congress Association.

Sharples, S., Shalloe, S., Burnett, G., \& Crundall, D, (2013). Journey decision making: The influence of dynamic information presented on Variable Message Signs, In: European Conference on Cognitive Ergonomics, ECCE 2013, Université de Toulouse Toulouse, France 2628 August 2013.

Southworth, M., \& Southworth, S. (1982). Maps: A visual survey and design guide. Boston: Little, Brown and Company. Ullman, B. R., Chrysler, S., Dudek, C. L., Trout, N. D., Ullman, G.L., (2008). 0-5256: Use of symbols and graphics on dynamic message signs. Project summary, 2-292008. Texas Department of Transportation. Accessed on line at http://library.ctr.utexas.edu/index.html 2 March 2009.

van der Mede, P., Coffeng, G., Martens, M., Janssen, W., \& Alkim, T. (1999). GRIOD II Graphical Route Information on Variable Message Signs. Ministry of Transport, Public Works and Water Management \& AVV Transportation Research Centre. Wickens, C. D., Lee, J. D., Liu, Y., \&

Gordon Becker, S. E. (2004). An introduction to human factors engineering (Second ed.). London: Pearson Education Ltd. 


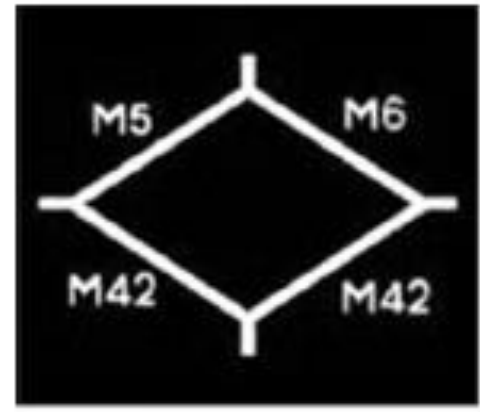

Design A

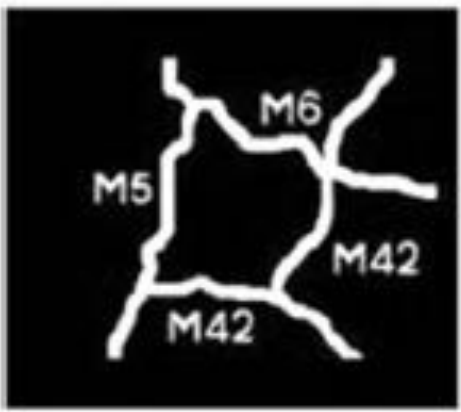

Design C

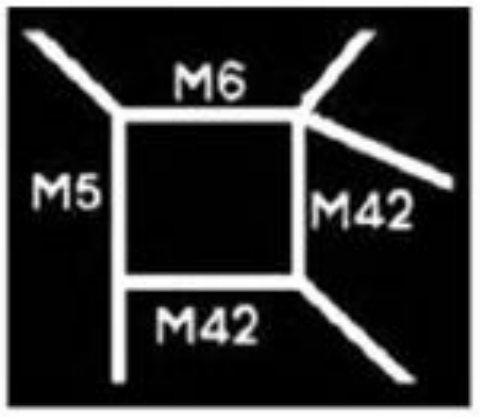

Design Aa

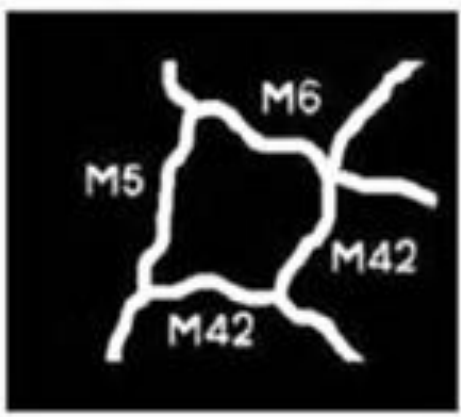

Design D

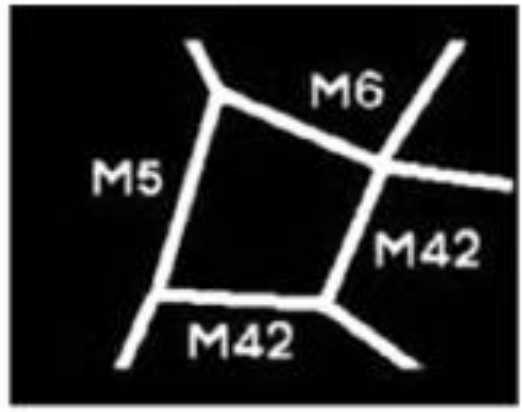

Design $\mathrm{B}$

Fig. 1. Basic network designs, 


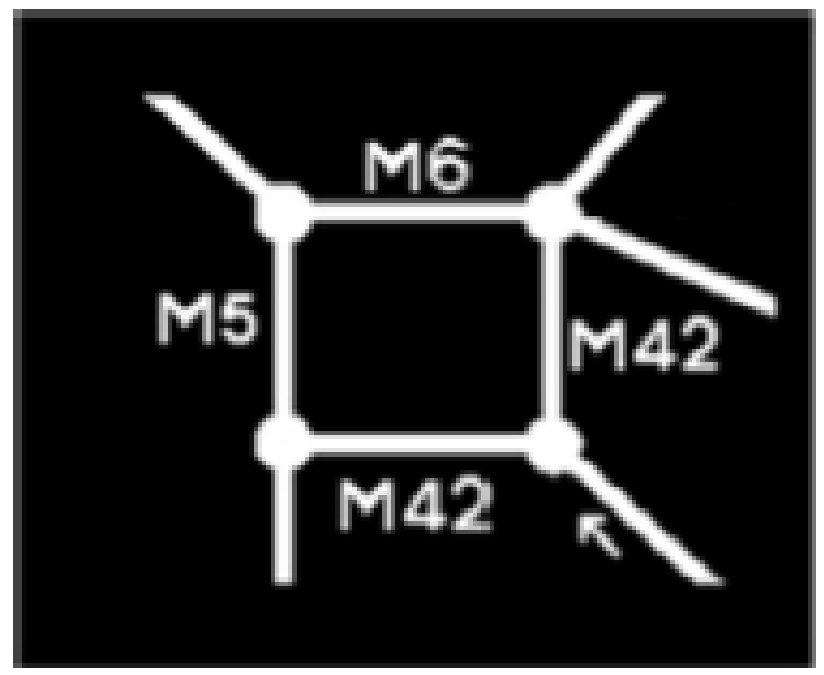

Fig. 2. Design $C$ with junction indicators and a driver location indicator. 

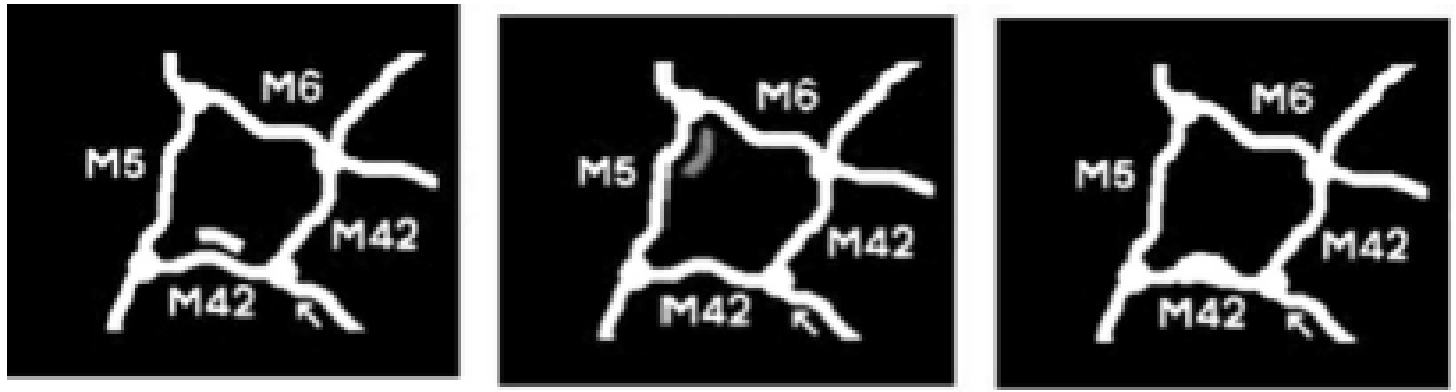

Congestion 1

\section{Congestion 2}

Congestion 3
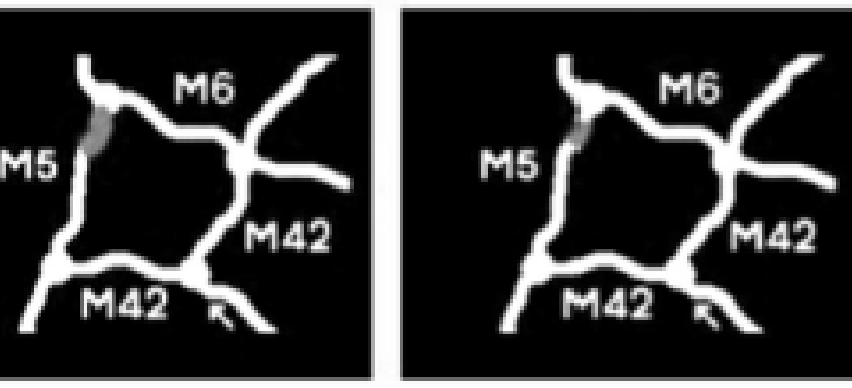

Congestion 4

Congestion 5

Fig. 3. Congestion representation designs (shown on network design C)

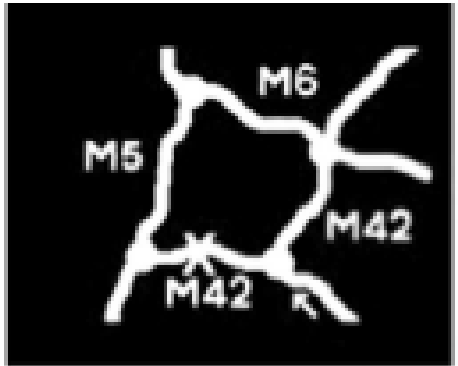

Closure 6

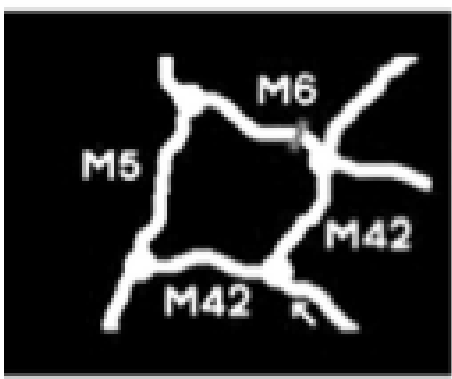

Closure 9
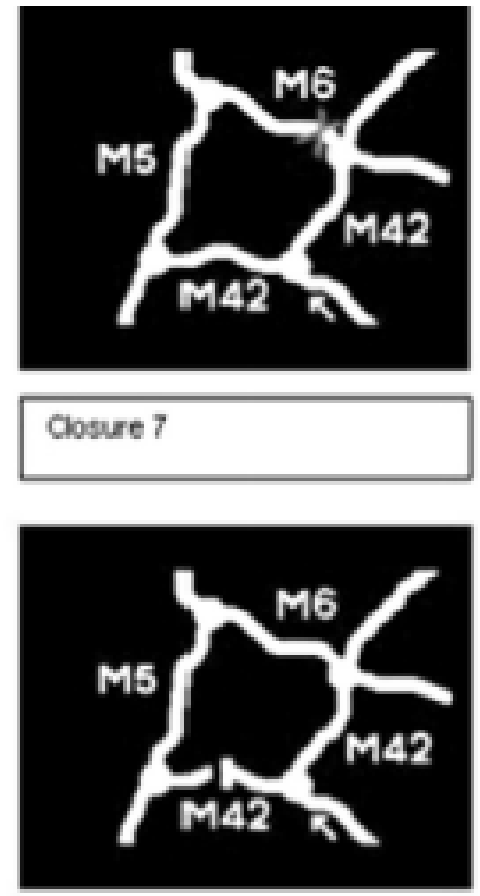

Closure 10

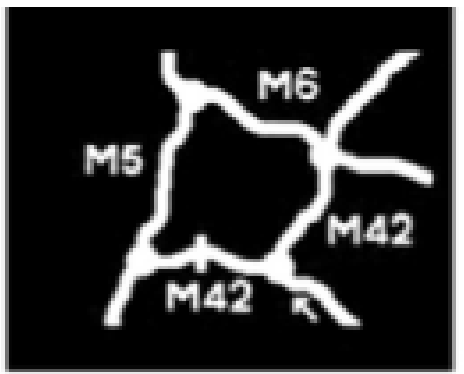

Cosure 8

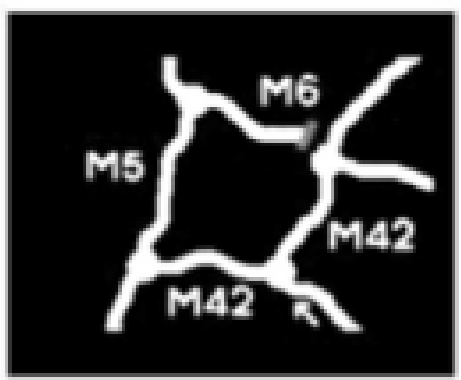

Closure 11

Fig 4. Road closure representations (shown on network design C). 


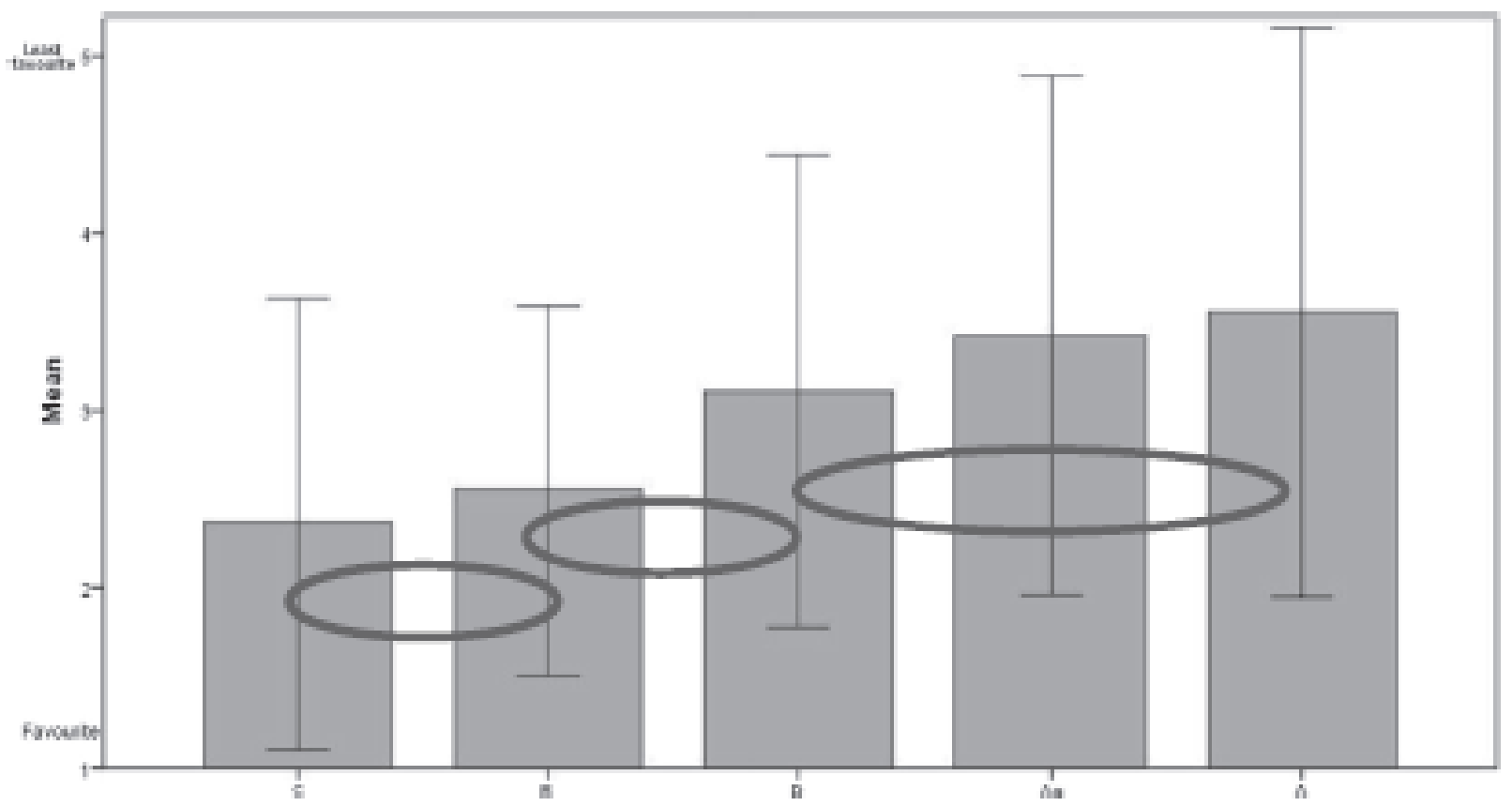

Fig. 5. Average ranks of preferences for basic designs (hoops illustrate statistically equiva lent groupings)- 


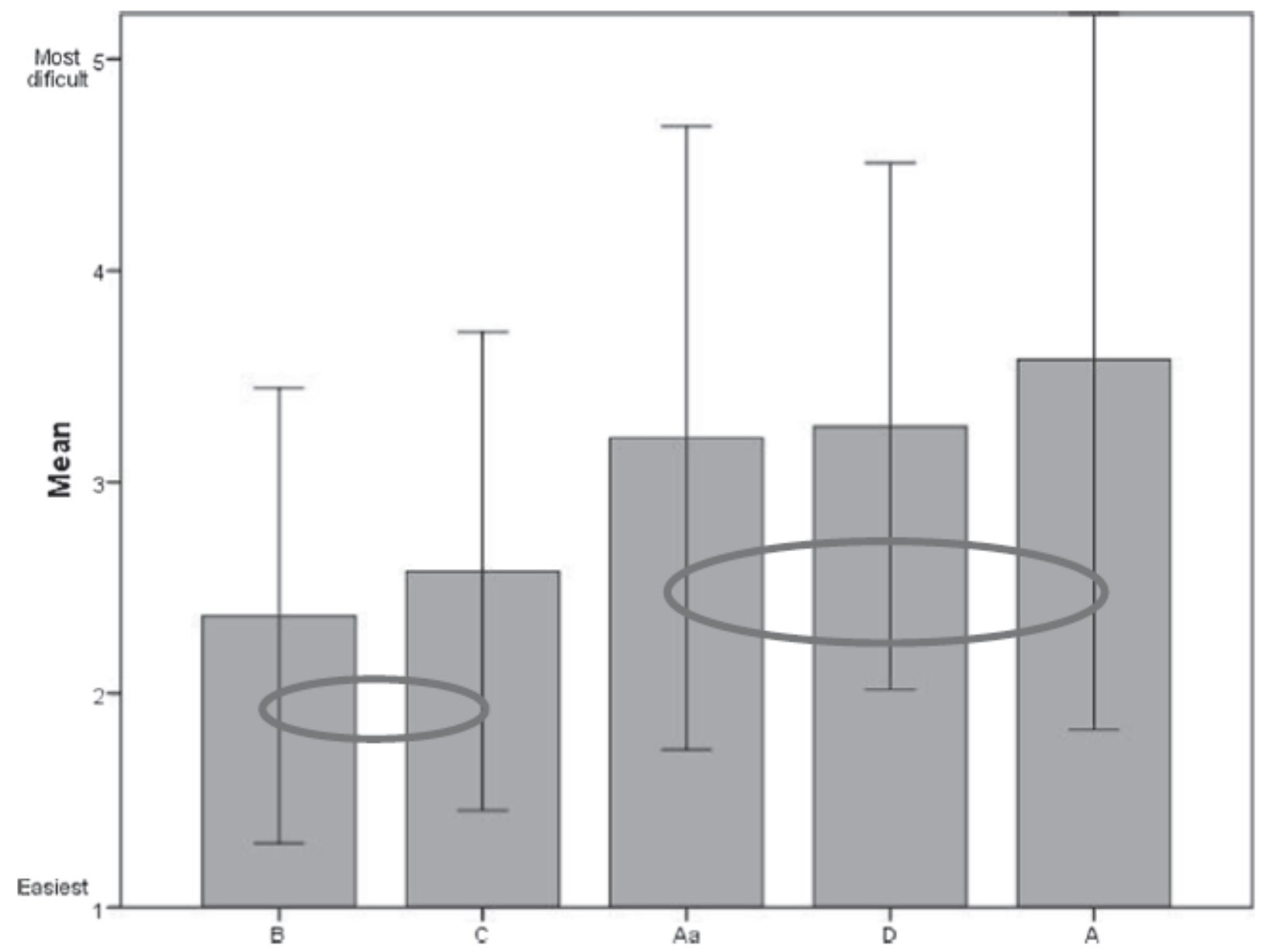

Fig. 6. Average ranks of ease of understanding (hoops illustrate statistically equivalent groupings). 


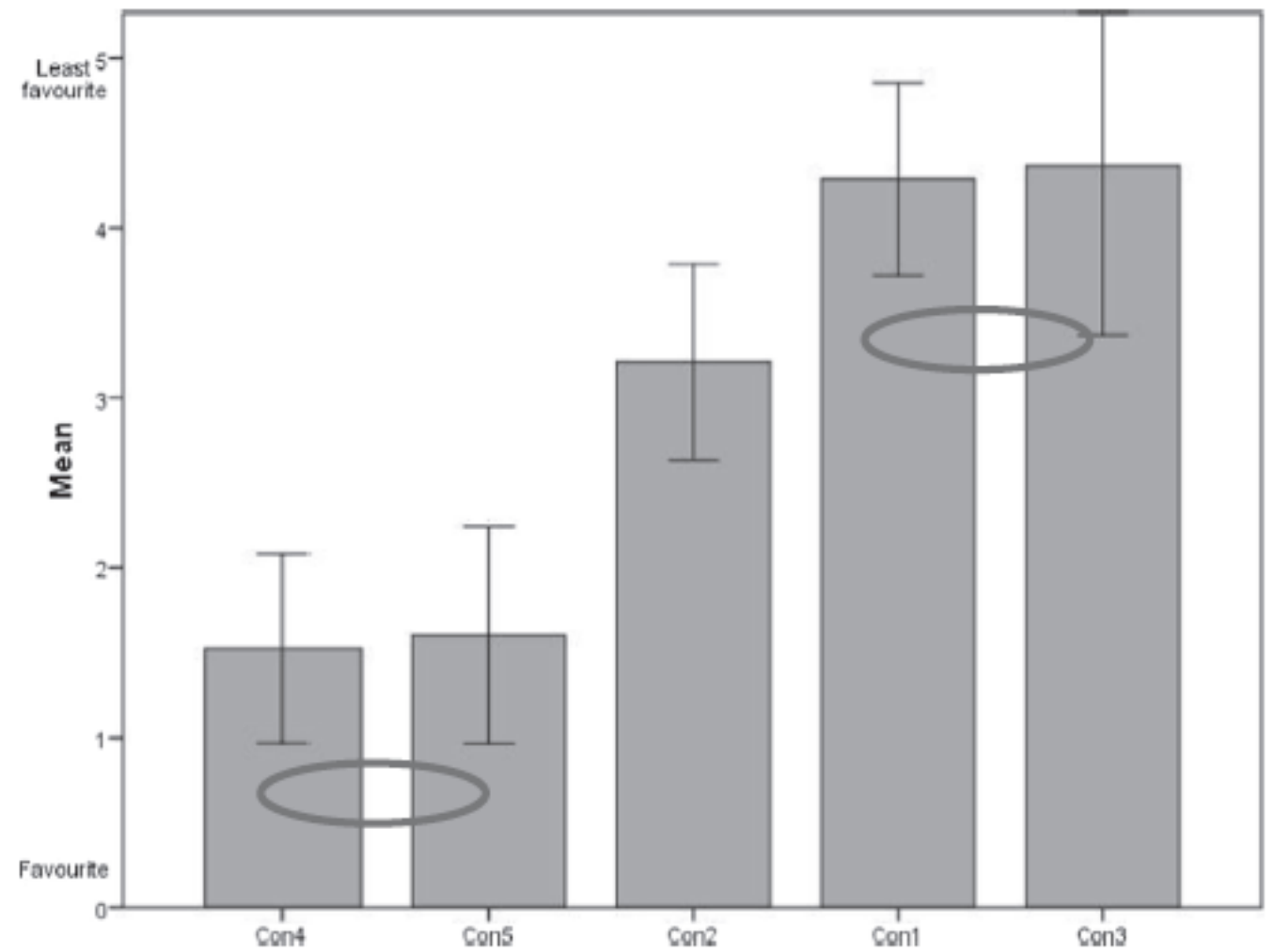

Fig. 7. Average ranks of preference for congestion designs (hoops illustrate statistically equivalent groupings).

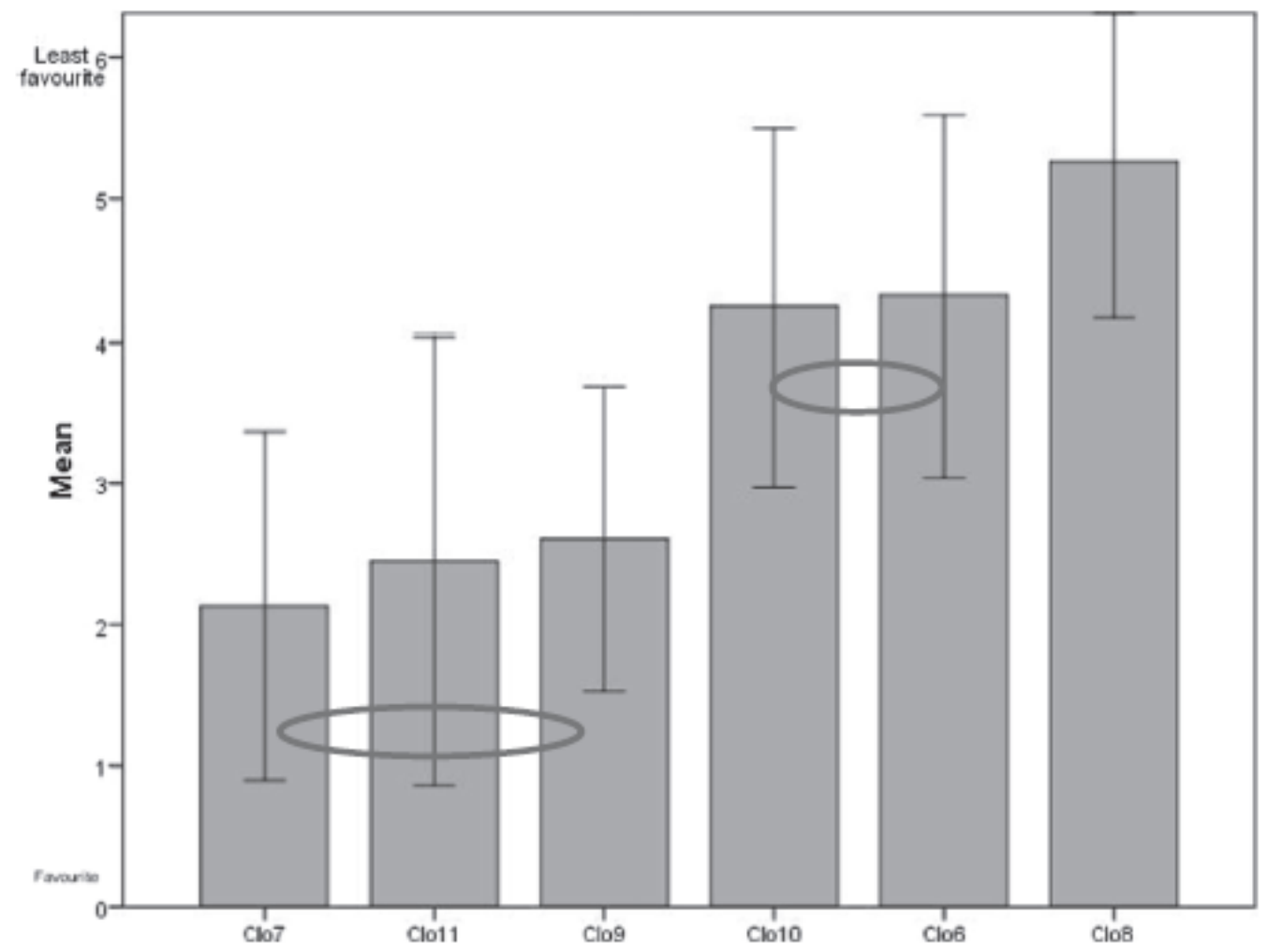

Fig. 8. Average ranks of preference for road closure designs (hoops illustrate statistically equivalent groupings). 


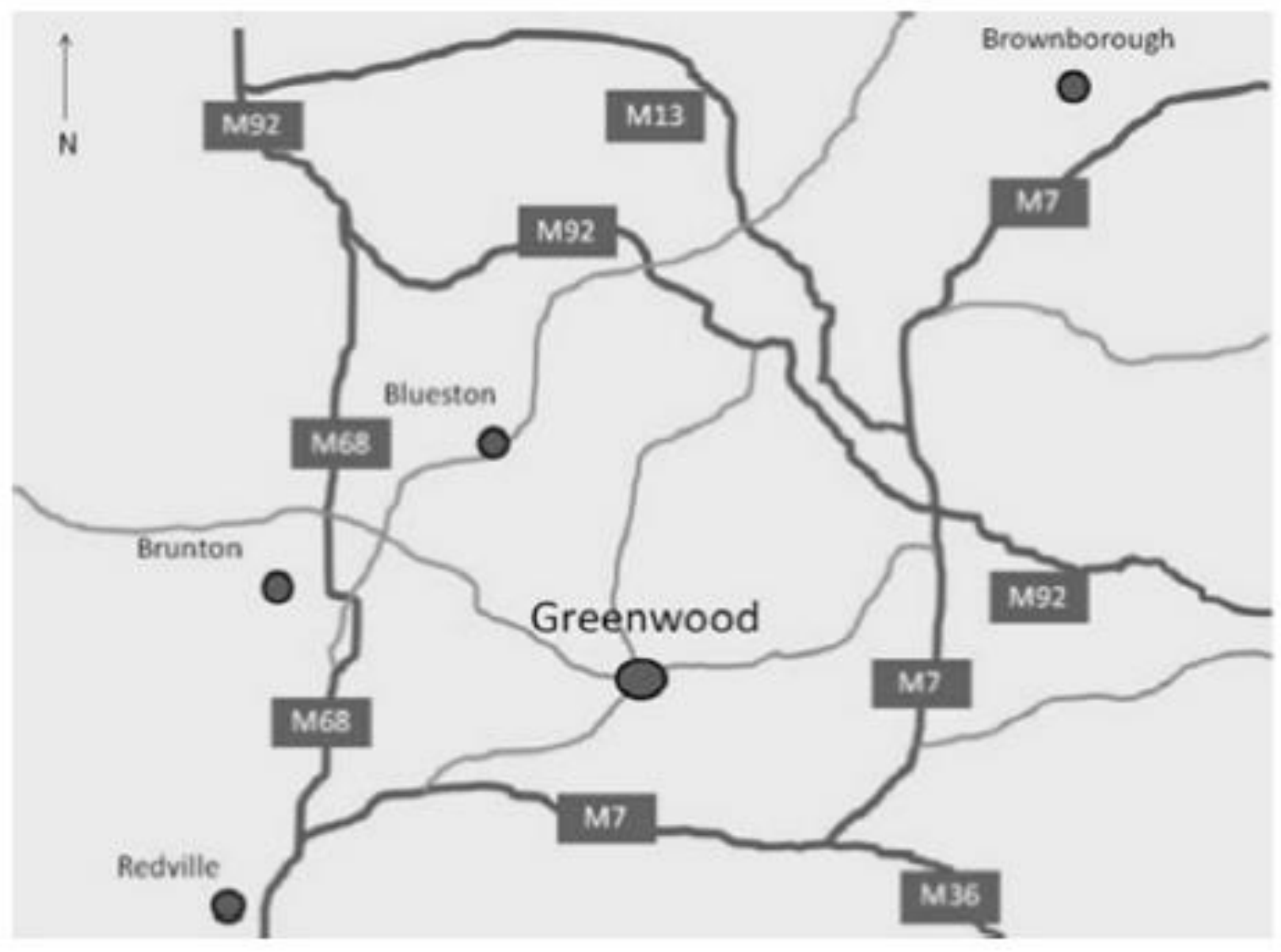

Fig. 9. Fictional network map used in study. 


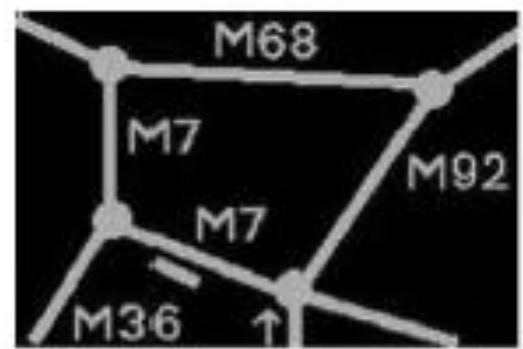

Network design B with congestion design 1

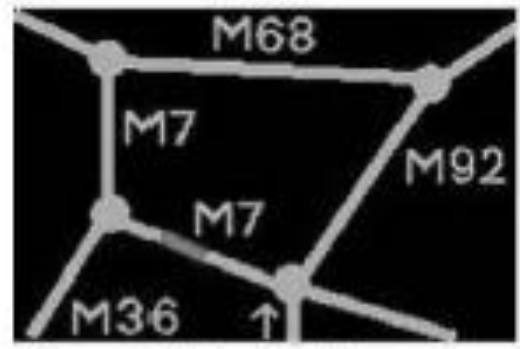

Network design B with congestiion design 5

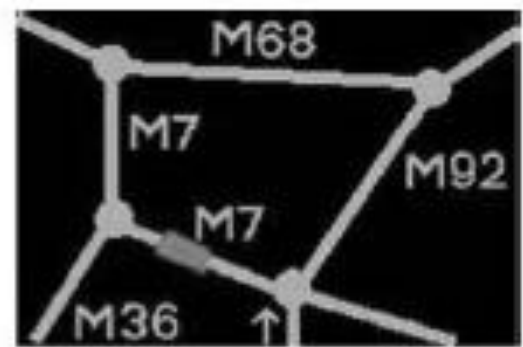

Network design B with congestion design 4

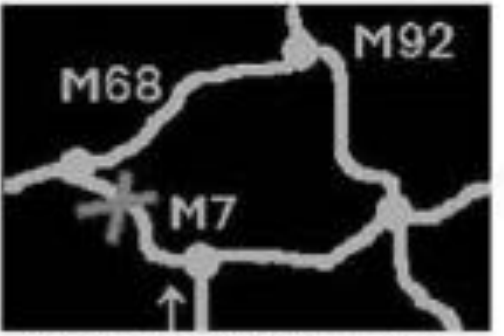

Network design $C$ with closure design 7

Fig. 10. Examples of congestion and closure designs shown on network designs $B$ and $C$.

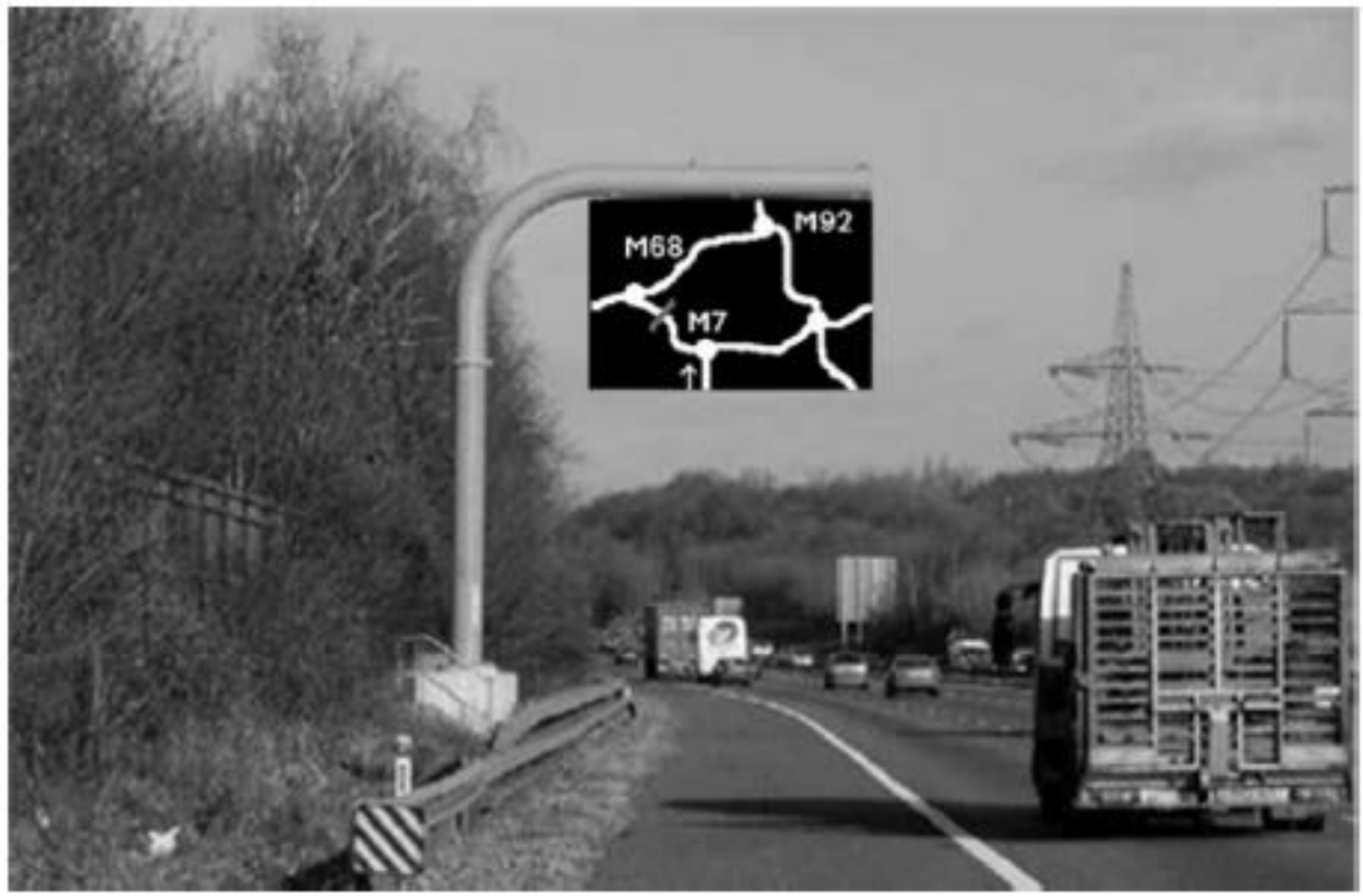

Fig. 11. Example of a GRP as presented to participants. 
Table 1

Methods used in study.

\begin{tabular}{|c|c|c|c|}
\hline Order & Method & Participants & Contr ibution to design \\
\hline 1 st & Acade mic expert focus group & Academic experts & $\begin{array}{l}\text { Draft CRIP designs } \\
\text { Future discussion topics } \\
\text { Design recammendations }\end{array}$ \\
\hline $2 \mathrm{nd}$ & Driver and industry expert focus groups & Drivers Industry experts & $\begin{array}{l}\text { Draft CRIP designs } \\
\text { Design recommendations } \\
\text { Review of existing designs }\end{array}$ \\
\hline 3 rd & Design drafting & Researchers Industry experts & Production of draft designs within known canstraints \\
\hline 4 th & Scenaria stuxdies & Drivers & $\begin{array}{l}\text { Assess drivers attitudes towards shortlisted draft designs } \\
\text { Assess driver comprehension of shor tlisted designs }\end{array}$ \\
\hline
\end{tabular}

Table 2

Discussion topics and conclusions from expert focus group.

\begin{tabular}{ll}
\hline Topic & Condusions \\
\hline How should a GRIP be orientated? & Further research required \\
$\begin{array}{l}\text { Provision of information on altemative routes } \\
\text { Level of detail to be induded }\end{array}$ & This could be useful and could improve traffic flow \\
& No consensus on whether trunk roads should be included as well as motorways as there were \\
operational issues to consider as well as issues of visual complexity so further research required & Further research required \\
Schematic versus topographic representation & Should be at least approximate rather than accurate as scale could influence the perception \\
Use of scale & of travel time between points \\
& Various options for coding levels of congestion induding the use of colour, line width \\
Representation of congestion & Generally agreed red should represent congestion along with the use of amber and green \\
Use of colour & for varying traffic states but issues of colour blindness were raised. \\
Junction numbers & Should be induded \\
Other suggestions & You are here' arrows and service stations to be shown
\end{tabular}

Table 3

Participant responses to type of information they would like to receive from signs advising of traffic conditions ( $n=26$ ).

\begin{tabular}{lllll}
\hline & $\begin{array}{l}\text { Length (miles) } \\
\text { of traffic queue }\end{array}$ & $\begin{array}{l}\text { Delay time } \\
\text { (mins) }\end{array}$ & $\begin{array}{l}\text { Travel time } \\
\text { (mins) }\end{array}$ & $\begin{array}{l}\text { Reasons for } \\
\text { delay }\end{array}$ \\
\hline $\begin{array}{l}\text { Participant responses } \\
\begin{array}{c}\text { Other information } \\
\text { (number of requests) }\end{array}\end{array}$ & $\begin{array}{l}9 \\
\text { Weather conditions (1); } \\
\text { congestion area (1) reducing travel times (1) }\end{array}$ & $\begin{array}{l}\text { Location of delay } \\
\text { (junction numbers) }\end{array}$ & $\begin{array}{l}13 \\
23\end{array}$ \\
\hline
\end{tabular}


Table 4

Images used in Activity 4 (images 1,3,4 and 5 reproduced with kind permission of T Alkim).

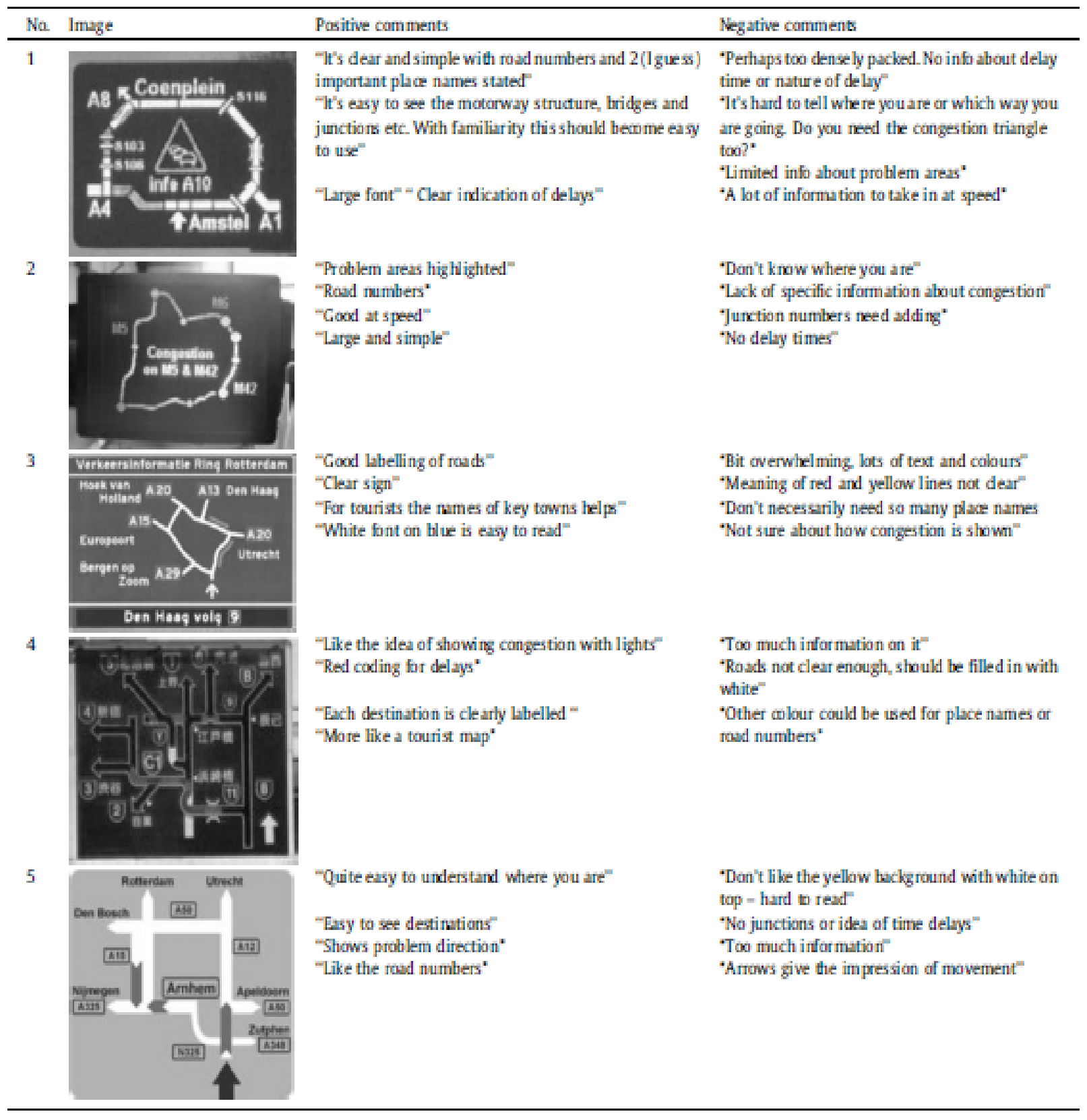

Table 5

Table of means of interpretation ratings for congestion designs.

\begin{tabular}{lll}
\hline Congestion design & Mean rating & Standard deviation \\
\hline Congestion 4 & 1.28 & 0.61 \\
Congestion 5 & 1.24 & 0.53 \\
Congestion 1 & 0.32 & 0.61 \\
\hline
\end{tabular}


Table 6

Analysis of interpretations of traffic congestion representations.

\begin{tabular}{|c|c|c|c|c|}
\hline $\begin{array}{l}\text { Design } \\
\text { number }\end{array}$ & Description & $\begin{array}{l}\text { Number of correct } \\
\text { interpretations }\end{array}$ & $\begin{array}{l}\text { Number of 'unknown' } \\
\text { interpretations }\end{array}$ & Most common misinterpretations \\
\hline Congestion 4 & Wide red line on carriageway & 54 & 6 & $\begin{array}{l}\text { Large obstruction on carriageway } \\
\text { Road works or serious incident }\end{array}$ \\
\hline Congestion 5 & Red line on carriageway & 54 & 8 & $\begin{array}{l}\text { Road closed or obstructed } \\
\text { Location on railway crossing or } \\
\text { junction }\end{array}$ \\
\hline Congestion 1 & $\begin{array}{l}\text { Yellow line alongside } \\
\text { carriageway }\end{array}$ & 8 & 36 & $\begin{array}{l}\text { Location of layby } \\
\text { Additional traffic lane open } \\
\text { Road works or other incident }\end{array}$ \\
\hline
\end{tabular}

Table 7

Table of means of in rpretation $\mathrm{r}$ ings for closure designs (higher rating indicates greater mean accuracy).

\begin{tabular}{lllll}
\cline { 1 - 1 } Closure design & & & Mean rating & Standard deviation \\
\cline { 1 - 1 } Closure 7 & & & 1.44 & 0.62 \\
Closure 9 & - & - & 1.41 & 0.57 \\
Closure 11 & $=$ & & 1.30 & 0.08 \\
Closure 10 & $=$ & 0.78 & 0.82 \\
\hline
\end{tabular}

Table 8

Analysis of interpretations of traffic closure representations.

\begin{tabular}{|c|c|c|c|c|}
\hline Design number & Description & $\begin{array}{l}\text { Number of correct } \\
\text { interpretations }\end{array}$ & $\begin{array}{l}\text { Number of 'unknown' } \\
\text { interpretations }\end{array}$ & Most common misinterpretations \\
\hline Cosure 7 & Red cross across carriageway & 78 & 10 & $\begin{array}{l}\text { Railway crossing or bridge } \\
\text { Obstruction or incident }\end{array}$ \\
\hline Cosure 9 & Red line across carriageway & 82 & 8 & $\begin{array}{l}\text { Obstruction in road } \\
\text { Delays/slow traffic } \\
\text { Road closed } \\
\text { Road end }\end{array}$ \\
\hline Gosure 11 & Red line and gap in carriageway & 81 & 8 & $\begin{array}{l}\text { Obstruction in road } \\
\text { Road closed } \\
\text { Road incomplete }\end{array}$ \\
\hline Cosure 10 & Yellow line and gap in carriageway & 58 & 15 & $\begin{array}{l}\text { Blockage in road } \\
\text { Road incomplete } \\
\text { Road under construction }\end{array}$ \\
\hline
\end{tabular}

